\title{
Library Service by Contract: A Joint Venture
}

\begin{abstract}
A mutually beneficial solution to the problem of university libraries' service to smaller libraries is exemplified by a long-term contract between the Graduate Research Center of the Southwest and Southern Methodist University. For two years the libraries in these research and educational institutions, located fifteen miles apart, have enjoyed such a contract, characterized by rapid messenger service, an annual contribution for acquisitions and cost-of-service reimbursements, and a full-time librarian's salary furnished by the special library. For special libraries with heavy demands, this type of agreement may be a realistic arrangement in which the smaller library "pays its way."
\end{abstract}

\section{D}

URING THE PAST FEW YEARS there has been interest in the problem of university service to special libraries. The dilemma of the university library in trying to meet increasing demands of smaller libraries without jeopardizing faculty and student service has been a difficult one. Most university libraries have continued to furnish interlibrary loans without charge, free reference service, and photocopy at cost-thus serving on a direct-cost basis. ${ }^{1} \mathrm{~A}$ more realistic solution is that exemplified by Stanford University in establishing its Technical Information Service for industry based on a fee per item delivered. This has proved quite successful in recovering both direct and indirect costs. ${ }^{2}$ The present paper describes another approach to the problem-that of service by contract

${ }^{1}$ Natalie N. Nicholson, "Service to Industry and Research Parks by College and University Libraries," Library Trends, XIV (January 1966), 262-72.

'Jack Pooler and David C. Weber, "The Technical Information Service in the Stanford University Libraries," College \& Research Libraries, XXV (September 1964), 393-99.

Mrs. Nott is GRCSW contract librarian at Southern Methodist University, and Mrs. Wheeler is librarian of the Graduate Research Center of the Southwest, Dallas. between a university library (Southern Methodist University) and a nearby special library (Graduate Research Center of the Southwest).

Southern Methodist University (SMU) only recently celebrated its fiftieth anniversity. It is a university of about seventy-eight hundred students offering graduate degrees in an ever-increasing number of fields. It has four libraries, the newest of which is the science library, built in 1961. It was partially financed by local industrial benefactors and is dedicated to the support of academic and industrial research in the region.

The Graduate Research Center of the Southwest (GRCSW) was chartered in 1961 by a group of Dallas businessmen concerned with the need to enhance the development of graduate education in science and engineering in the Southwest. It was established as a nonprofit educational institution with a two-fold purpose: (1) to serve as a center for postdoctoral study, and to cooperate with colleges and universities in the region in training graduate students; and (2) to sponsor basic research in fields of major importance to present-day science 
and technological development. Interdisciplinary divisions in various degrees of development have been formed in the fields of atmospheric and space sciences, geosciences, mathematical physics, biology, and materials sciences.

To date the GRCSW policy has been to maintain a small specialized library. Its broad objective is to "provide library service equivalent to that of a large university library through ties to a coordinating area library system." 3 Consequently, a contract was executed, effective September 1964, between SMU and GRCSW, the pertinent aspects of which are as follows:

GRCSW is responsible to SMU for:

1. $\$ 5000$ annual fee to be used for SMU acquisitions; GRCSW has the privilege of making recommendations.

2. Salary (plus normal SMU fringe benefits) for a full-time librarian to work in the SMU science library exclusively for GRCSW.

3. $15 \notin$ per page for Xerox 914 reproduction and comparable charges for use of other photolab equipment.

4. Messenger service twice daily between SMU and GRCSW.

5. Miscellaneous expenses including a 20 per cent overhead charge, postage, and telephone costs.

6. Direct costs of material obtained in lieu of interlibrary loans from other libraries.

SMU is responsible to GRCSW for:

1. Loan of their books, journals (photocopies when requested, or when article is short), reports, government documents, and maps.

2. Interlibrary loan service for material requested which is not in SMU libraries.

3. Office space and supplies for librarian working for GRCSW.

4. Supporting capabilities of SMU science library staff.

${ }^{3}$ Graduate Research Center of the Southwest, Plan for GRCSW Library Service, [1964], p. 1.
5. Study room reserved for GRCSW personnel.

6. Fifty copies of each monthly acquisitions bulletin.

GRCSW personnel may initiate requests from SMU by:

7. Photolab and equipment for reading microfilm, microfiche, and microcards.

1. Contacting their librarian at GRCSW.

2. Phoning their librarian at SMU (a telephone recorder provides the means for leaving requests, day or night, if no one is in the SMU office).

3. Going to SMU to use and check out material personally.

Most requests are initiated at the GRCSW library, for much of what is needed may be found there. The two librarians (at SMU and GRCSW) are in constant telephone contact.

Both SMU and GRCSW feel that the contract has been mutually beneficial. In the fiscal year ending June 30,1966 , a total of 5,261 items was supplied by SMU; of these, 550 items were obtained from other libraries. GRCSW paid a total of approximately $\$ 20,200$ to SMU during the same time period, of which $\$ 5000$ was invested in acquisitions.

The obvious advantage to GRCSW is the availability of a large collection of library materials conveniently located and efficiently serviced, furnished on a mutually agreed cost basis. The SMU science library, besides pursuing its own goals of academic service, benefits by continuing to develop equipment, personnel, and experience in its broad plan of supporting academic and industrial research in the region. Both participants have found that an annual contribution for acquisitions and a cost-of-service fee rather than a charge per item has simplified the quarterly billing procedures. An additional advantage has been that of having a GRCSW librarian on the job at SMU, for this keeps GRCSW requests from disrupting service for faculty and students at SMU. 
Although the contract has been extremely successful in its two years of existence, the librarians involved feel that there are questions which could be posed for future consideration by both institutions:

1. Should cooperative acquisitions be developed to a greater extent? Too often the same material is purchased by both libraries primarily for use by GRCSW scientists.

2. Is the financial arrangement fair to both institutions?
3. Has GRCSW become overly dependent on SMU to the extent that it has not developed its own resources adequately or efficiently?

This article was written in response to considerable interest shown in the joint venture to provide adequate library service for GRCSW. It appears to be a workable, practical solution to the problems of university service to special libraries. Perhaps other libraries could benefit from such an arrangement to their mutual advantage.

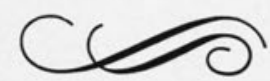

